\title{
Technical note: At-line prediction of mineral composition of fresh cheeses using near-infrared technologies
}

\author{
C. L. Manuelian, ${ }^{*}$ S. Currò, ${ }^{*}$ G. Visentin, ${ }^{*}$ M. Penasa, ${ }^{*}$ M. Cassandro, ${ }^{*}$ C. Dellea, $†$ M. Bernardi, $\dagger$ \\ and M. De Marchi*1 \\ *Department of Agronomy, Food, Natural Resources, Animals and Environment (DAFNAE), University of Padova, Viale dell'Università 16, \\ 35020 Legnaro (PD), Italy \\ †Department of Research and Development, Granarolo Group, via Cadriano 27/2, 40127 Bologna (BO), Italy
}

\begin{abstract}
Milk and dairy products are important sources of macro- and trace elements for human health. However, fresh cheeses usually have a lower mineral content than other cheeses, and this makes mineral prediction more difficult. Although mineral prediction in several food matrices using infrared spectroscopy has been reported in the literature, very little information is available for cheeses. The present study was aimed at developing near-infrared reflectance (NIR, 866-2,530 nm) and transmittance (NIT, $850-1,050 \mathrm{~nm}$ ) spectroscopy models to predict the major mineral content of fresh cheeses. We analyzed samples of mozzarella $(\mathrm{n}=130)$ and Stracchino $(\mathrm{n}=118)$ using reference methods and NIR and NIT spectroscopy. We developed prediction models using partial least squares regression analysis, and subjected them to cross- and external validation. Average Na content was 0.15 and $0.22 \mathrm{~g} / 100 \mathrm{~g}$ for mozzarella and Stracchino, respectively. The NIR and NIT spectroscopy performed similarly, with few exceptions. Nevertheless, none of the prediction models was accurate enough to replace the current reference analysis. The most accurate prediction model was for the $\mathrm{Na}$ content of mozzarella cheese using NIT spectroscopy (coefficient of determination of external validation $=$ $0.75)$. We obtained the same accuracy of prediction for $\mathrm{P}$ in Stracchino cheese with both NIR and NIT spectroscopy. Our results confirmed that mineral content is difficult to predict using NIT and NIR spectroscopy.
\end{abstract} Key words: mozzarella cheese, Stracchino cheese, mineral, sodium

\section{Technical Note}

Milk and dairy products are important sources of macro- and trace elements for human health. It has

Received January 24, 2017.

Accepted April 26, 2017.

${ }^{1}$ Corresponding author: massimo.demarchi@unipd.it been estimated that milk and dairy products provide the greatest dietary amounts of $\mathrm{Ca}$ and $\mathrm{P}$, at 59 and $27 \%$ of human daily intake, respectively (LombardiBoccia et al., 2003). They also provide about $7 \%$ of the daily intake of $\mathrm{Na}, 9 \%$ of $\mathrm{K}$, and $11 \%$ of $\mathrm{Mg}$ (LombardiBoccia et al., 2003). Calcium and $\mathrm{P}$ are essential for the health of bones and teeth (Bonjour et al., 2009), but $\mathrm{Na}$ has been implicated in hypertension and cardiovascular disease (Matthews and Strong, 2005; Aburto et al., 2013). The European Food Safety Authority and the World Health Organization have recommended a daily $\mathrm{Na}$ intake of less than $2.4 \mathrm{~g}$, and mandatory labeling regulations require that "salt" (defined as $\mathrm{Na}$ $\times 2.5$ ) be listed on product labels [Regulation (EU) No 1169/2011)] to help consumers in their purchasing decisions. Consequently, cheese producers may need to develop at-line tools to facilitate the determination of mineral content in cheese manufacturing, comply with labeling requirements, and add more detailed health claims to their products.

Infrared spectroscopy offers a rapid, objective, and nondestructive analysis of the sample at a much lower cost than common reference laboratory methods. Spectra collection can be performed using infrared technologies in reflectance or transmittance mode, but differences in accuracy have been reported for cheese. Moisture has been more accurately predicted in transmittance mode, but sensory and rheological attributes have been more accurately predicted in reflectance mode (Woodcock et al., 2008). To our knowledge, only a few studies have developed prediction models for the mineral composition of cheese using infrared spectroscopy in reflectance mode; Karoui et al. (2006a) used mid-infrared spectroscopy in transmittance mode to predict the $\mathrm{NaCl}$ content of Emmentaler cheese, and Manuelian et al. (2017b) used transmittance mode to predict the content of several minerals in cheese. The aims of the present study were to (1) develop nearinfrared reflectance (NIR) and near-infrared transmittance (NIT) spectroscopy models to predict the major mineral composition of fresh cheeses, and (2) compare 
the effectiveness of these 2 infrared approaches in predicting the mineral content of cheese.

We collected a total of 130 mozzarella and 118 Stracchino samples from April to September 2016 in a large commercial Italian cheesemaking factory (Granarolo S.p.A, Bologna, Italy). Both fresh cheese varieties were made with pasteurized partially skimmed cow's milk. Mozzarella cheese production involved heating the milk to 33 to $39^{\circ} \mathrm{C}$. Then, microbial rennet, a commercial culture starter and, if needed, citric acid (to correct milk acidity), were added to the milk, which was kept at 32 to $33^{\circ} \mathrm{C}$. After milk coagulation and setting, the curd was broken with a metallic tool called a spino. Part of the whey was drained, and the curd was left to acidify in the remaining whey until it reached a $\mathrm{pH}$ of 5.3 to 5.4 and the cheesemaker determined it to be mature by a spinning test. The mature curd was completely drained, comminuted, and forwarded to the stretching machine. After complete spinning, the plasticized curd was shaped into spherical shapes and put into hardening and brining vats to develop its peculiar thin skin. Finally, the pieces of mozzarella were packaged in plastic bags in a light microfiltered brine. For Stracchino, milk was heated to 37 to $38^{\circ} \mathrm{C}$ and pumped into a cheese vat, where calf rennet, a commercial culture starter, and organic acid (to correct milk acidity) were added. After coagulation the curd was roughly cut, left for a rest period, and then separated from the whey. To reduce $\mathrm{pH}$ and drain excess whey, the curd was distributed into plastic rectangular molds and stewed for $5 \mathrm{~h}$ at 23 to $30^{\circ} \mathrm{C}$. The mature curd was then placed in refrigerated brine for 4 to $5 \mathrm{~d}$ at $4^{\circ} \mathrm{C}$ before ripening.

For analysis, each sample (drained from the light brine when necessary) was ground using a MasterChef 8000 robot (Moulinex, Groupe Seb, Milan, Italy) at the cheesemaking factory and split in 2 aliquots. The subsample for chemical analysis was put in an airtight container to preserve product features; transported at $4^{\circ} \mathrm{C}$ to the laboratory of the Department of Agronomy, Food, Natural Resources, Animals and Environment of the University of Padova (Legnaro, Italy); and analyzed within $24 \mathrm{~h}$ of collection. Inductively coupled plasma optical emission spectrometry (ICP-OES; Ciros Vision EOP, Spectro Analytical Instruments GmbH, Kleve, Germany) was used to quantify $\mathrm{Ca}, \mathrm{Na}, \mathrm{P}, \mathrm{Mg}$, and $\mathrm{K}$ contents, following the procedure indicated by De Marchi et al. (2017). The subsample for the infrared analysis was directly used to fill a Petri cup (diameter $100 \mathrm{~mm}$, depth $15 \mathrm{~mm}$ ) and scanned at the cheesemaking factory using 2 infrared instruments, one working in reflectance mode and the other in transmittance. For reflectance mode, each spectrum was an average of 16 sub-spectra recorded at different points by rotating the Petri cup automatically in a Tango Fourier transform
NIR spectrometer (Bruker, Billerica, MA) and recorded as $\log _{10}(1 /$ reflectance $)$. The Tango spectrometer operated at room temperature, scanning every $4 \mathrm{~cm}^{-1}$ from 3,952 to $11,540 \mathrm{~cm}^{-1}$, corresponding to 866 to 2,530 $\mathrm{nm}$. For transmittance mode, each spectrum was an average of 32 sub-spectra recorded at different points by rotating the Petri cup automatically in a FoodScan Dairy Analyzer (Foss Electric A/S, Hillerød, Denmark) and recorded as $\log _{10}(1 /$ transmittance). The FoodScan Dairy Analyzer operated at room temperature, scanning every $2 \mathrm{~nm}$ from 850 to $1,050 \mathrm{~nm}$. In addition, cheese moisture, fat, and protein contents were indirectly determined at the cheesemaking factory using the FoodScan Dairy Analyzer precalibrated with Foss Artificial Neural Networks Dairy Calibration, as reported by Manuelian et al. (2017a).

Prediction models were carried out using SAS version 9.4 (SAS Institute Inc., Cary, NC). Normality was assessed by visual inspection and by the Shapiro-Wilk test statistic, and $\log _{10}$ transformation was applied to K content of both the mozzarella and Stracchino cheeses to normalize the data. Concentration outliers were defined as values greater than 3 standard deviations from the mean of each mineral. Following this procedure, 3 observations for the $\mathrm{P}$ content of mozzarella and 1 observation for the $\mathrm{Na}$ content of Stracchino were discarded. Spectral data outliers were assessed using principal component analysis and the Mahalanobis distance, calculated according to Brereton (2015). The plot of the first principal component versus the second (which together explained more than $99 \%$ of the total spectral variation) did not point out any obvious spectral outliers. Partial least squares regression analysis (SAS version 9.4; SAS Institute Inc.) was carried out to develop the prediction models, which included the vector of each mineral as a dependent variable and the matrix of transmittance or reflectance as predictors. For each mineral, we split the data set into a calibration set ( $75 \%$ of observations) and a validation set ( $25 \%$ of observations). The calibration set was used to generate the prediction models, and the validation set to externally validate the models and quantify their predictive ability. We repeated this process 4 times for each trait: the first iteration excluded the first of every 4 observations from the calibration set (and therefore included them in the validation set), the second iteration excluded the second observation of every 4 , and so on for the third and fourth iterations. One-at-a-time cross-validation was also performed in the calibration set. The mean, standard deviation, and range for each mineral in each iteration were similar for both the calibration and validation sets. We determined the optimal number of model factors as the minimum number of factors needed to achieve the lowest root mean predict- 
Table 1. Mineral composition (g/100 g) of mozzarella and Stracchino cheese samples

\begin{tabular}{|c|c|c|c|c|c|c|c|c|c|c|}
\hline Mineral & \multicolumn{5}{|c|}{ Mozzarella $(\mathrm{n}=130)$} & \multicolumn{5}{|c|}{ Stracchino $(\mathrm{n}=118)$} \\
\hline $\mathrm{Ca}$ & 0.332 & 0.045 & 13.6 & 0.229 & 0.510 & 0.351 & 0.071 & 20.1 & 0.257 & 0.598 \\
\hline $\mathrm{Mg}$ & 0.012 & 0.002 & 16.9 & 0.009 & 0.020 & 0.015 & 0.003 & 18.6 & 0.010 & 0.021 \\
\hline $\mathrm{Na}$ & 0.152 & 0.057 & 37.3 & 0.024 & 0.290 & 0.214 & 0.080 & 38.6 & 0.060 & 0.472 \\
\hline $\mathrm{P}$ & 0.238 & 0.024 & 12.7 & 0.187 & 0.370 & 0.251 & 0.054 & 21.4 & 0.170 & 0.419 \\
\hline
\end{tabular}

ed residual sum of squares. For goodness-of-fit, we used the coefficients of determination of cross- and external validation $\left(\mathbf{R}^{2} \mathbf{C V}\right.$ and $\mathbf{R}^{2} \mathbf{E x} \mathbf{V}$, respectively), and the standard errors of prediction of cross- and external validation (SEPCV and SEPExV, respectively). In the validation set, we calculated the ratio of prediction to deviation (RPD) for each mineral as the ratio of the SEPExV to the standard deviation of the validation samples (Manley, 2014). We calculated bias as the average difference between the reference value and the respective predicted value for each observation, and used a $t$-test to determine whether the bias was statistically different from 0 . Reference values for each model were linearly regressed on the respective predicted value to obtain the linear regression coefficient (slope), and we carried out a $t$-test to determine whether the slope was statistically different from 1 .

The moisture, fat, and protein contents of the mozzarella cheese samples averaged $65.32,15.06$, and $16.66 \%$, respectively, in agreement with the results of De Angelis et al. (2008) and Manuelian et al. (2017a). The average values for the Stracchino samples were 65.72, 15.14, and $14.29 \%$, respectively, similar to the findings of Lante et al. (2006). Values for K and Na exhibited the greatest variability of the studied minerals in both mozzarella and Stracchino cheeses (Table 1). As expected, Ca and $\mathrm{P}$ were the most abundant. Manuelian et al. (2017a) reported similar values for the major mineral content of cow's milk mozzarella, and Gambelli et al. (1999) determined comparable values for $\mathrm{Ca}$ and $\mathrm{Mg}$ in the same cheese. The mineral content of Stracchino was similar to that reported for Squacquerone (Lante et al., 2006), a type of Stracchino cheese. Some authors have reported a greater $\mathrm{Na}$ content in mozzarella, with a range of 0.28 to $1.01 \mathrm{~g} / 100 \mathrm{~g}$ of cheese (Johnson et al., 2009; Agarwal et al., 2011). However, authors disagree about the mineral content of dairy products, because it can change according to factors such as the analytic method (Lante et al., 2006), the type of cheesemaking process (e.g., acid/rennet coagulation, starter cultures, rennet type, $\mathrm{pH}$ of whey), and the type of milk (e.g., cow vs. buffalo and pasteurized vs. raw; Jana and Mandal, 2011). Salting is a crucial step in cheese manufacturing, and $\mathrm{NaCl}$ contributes the largest amount of $\mathrm{Na}$ in cheese. The low amount of $\mathrm{Na}$ in mozzarella and Stracchino cheese from the present study was mainly a consequence of the strategy adopted by the dairy company to reduce $\mathrm{Na}$ content by substituting $\mathrm{NaCl}$ with other salts such as $\mathrm{KCl}$, which in turn could explain the higher $\mathrm{K}$ content compared with other studies (Gambelli et al., 1999).

Average absorbance spectra for mozzarella and Stracchino cheeses obtained in transmittance and reflectance mode are depicted in Figure 1. The absorbance pattern was similar in both cheeses, although mozzarella presented slightly greater absorbance than Stracchino. The NIR spectra followed a similar shape to those previously reported in cheese (Karoui et al., 2006b; Lucas et al., 2008; González-Martín et al., 2011). Although minerals do not have a specific absorption band in the infrared spectroscopy region, $\mathrm{Na}$ prediction models have been related to the effect of that element on the water absorption band (Begley et al., 1984; BüningPfaue, 2003). Transmittance spectra exhibited a peak at around $984 \mathrm{~nm}$, which corresponded to a $\mathrm{OH}$ second overtone (Lucas et al., 2008). We also detected this peak in reflectance spectra, but with a lower absorbance. In reflectance spectra, peaks around 1,452 and 1,938 have been also related to water, with a $\mathrm{OH}$ stretch first overtone and a $\mathrm{OH}$ bend second overtone (Lucas et al., 2008).

Although it is commonly agreed that the higher the RPD the better the model, researchers do not agree on the interpretation of RPD at the low end of the range. More conservative authors have indicated that RPD values $>3$ can be used for screening (Manley, 2014), but other authors have considered values above 2.5 (Sinnaeve et al., 1994) or even 2 (Karoui et al., 2006a) as good enough for screening purposes. Karoui et al. (2006a) also reported that a $\mathrm{R}^{2} \mathrm{CV}$ or $\mathrm{R}^{2} \mathrm{ExV}$ from 0.50 to 0.65 allowed them to distinguish between high and low concentrations; from 0.66 to 0.81 indicated approximate quantitative prediction; from 0.82 to 0.90 revealed good prediction; and above 0.91 was excellent. We observed lower $\mathrm{R}^{2} \mathrm{ExV}$ than $\mathrm{R}^{2} \mathrm{CV}$ in both mozzarella (Table 2) and Stracchino cheese (Table 3). For each cheese and mineral, the bias and the slope calculated 
using the validation set did not differ from 0 and 1 , respectively. We obtained slightly higher $\mathrm{R}^{2}$ using NIR than NIT, except for the external validation of $\mathrm{Ca}$ and $\mathrm{Na}$ in mozzarella (Table 2), and for cross- and external validation of $\mathrm{Na}$ in Stracchino (Table 3). The best prediction model in mozzarella cheese was for Na using NIT ( $\mathrm{R}^{2} \mathrm{ExV}$ 0.75; Table 2), and the best prediction model in Stracchino cheese was for $\mathrm{P}$ using NIT and NIR ( ${ }^{2}$ ExV 0.74 and 0.75 , respectively; Table 3 ). The poor predictions we obtained were expected, because inorganic compounds do not interact with infrared radiation, and the mineral concentrations in the samples were close to the limit of sensitivity $(<0.1 \%)$ indicated for infrared spectroscopy (Iwamoto et al., 1995).

To our knowledge, only few studies have developed mineral predictions in cheeses using NIR and NIT. Moreover, those studies used different techniques to obtain reference data, such as a chloride analyzer, atomic absorption or an emission spectrometer (Lucas et al., 2008), or potentiometric titration (Karoui et al., 2006a). Only González-Martín et al. (2011) and Manuelian et al. (2017b) used the same reference analysis as the present study (inductively coupled plasma optical emission spectrometry). González-Martín et al. (2011)

A) NIT, $850-1,050 \mathrm{~nm}$

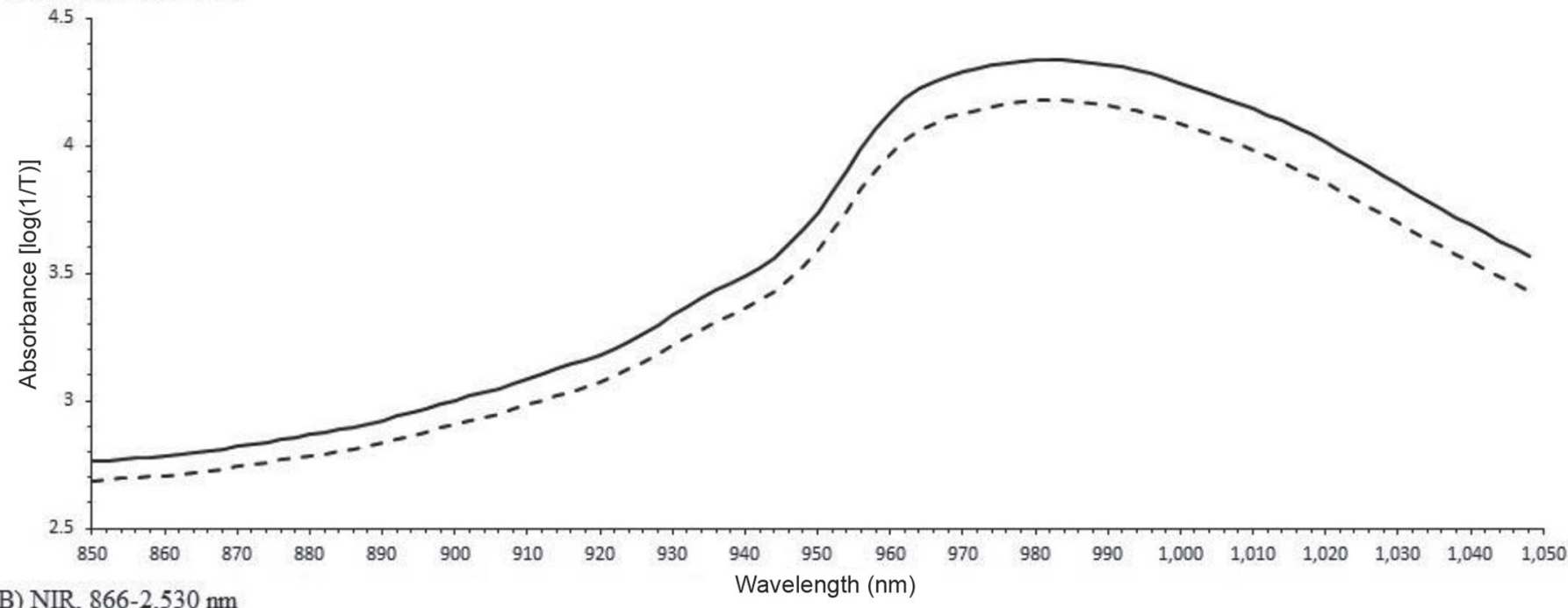

B) NIR, $866-2,530 \mathrm{~nm}$

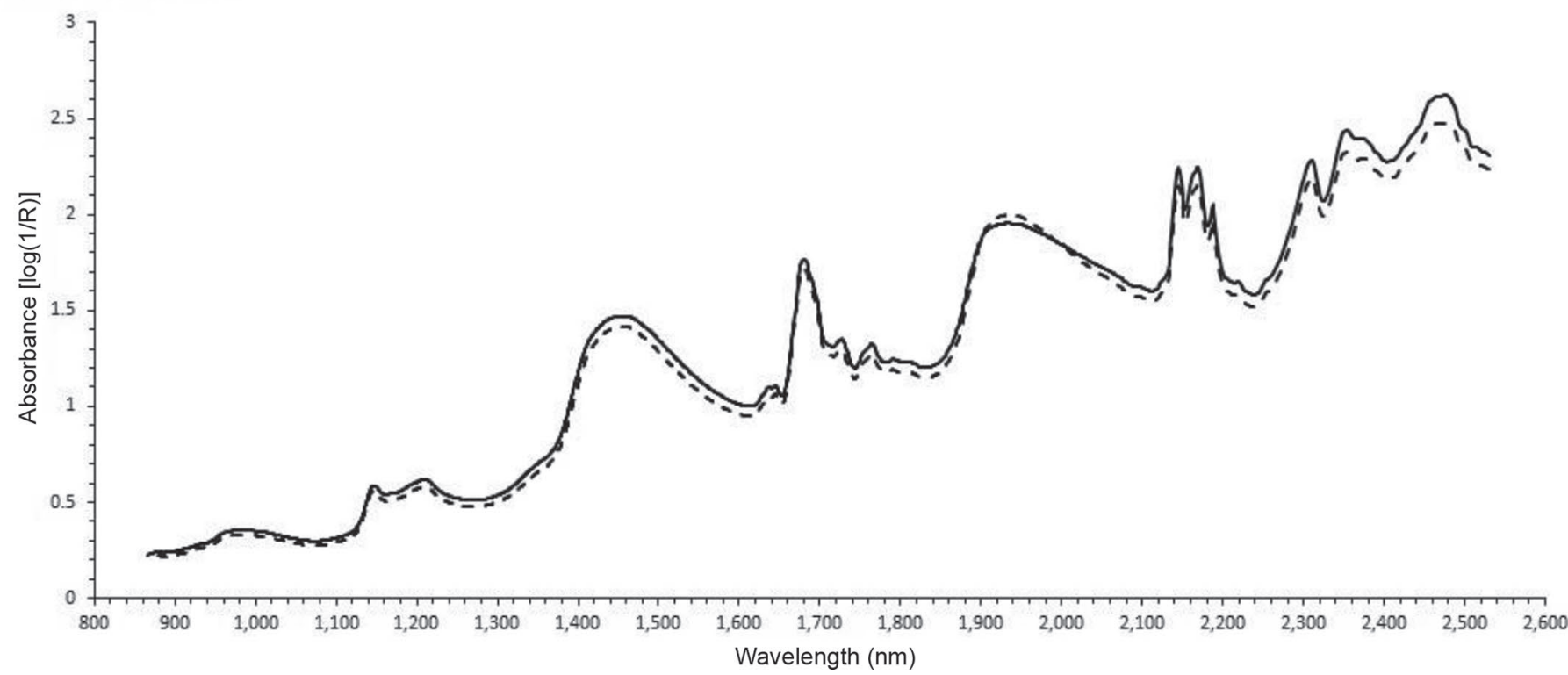

Figure 1. Average raw spectra of mozzarella (solid line) and Stracchino (dashed line) cheese using (A) near-infrared transmittance (NIT), and (B) near-infrared reflectance (NIR) spectroscopy. $\mathrm{T}=$ transmittance; $\mathrm{R}=$ reflectance. 
Table 2. Fitting statistics ${ }^{1}$ of prediction models for mineral composition (mean of 4 iterations) of mozzarella cheese using near-infrared transmittance (NIT) and near-infrared reflectance (NIR) spectroscopy

\begin{tabular}{|c|c|c|c|c|c|c|c|c|}
\hline \multirow[b]{2}{*}{ Mineral } & \multicolumn{3}{|c|}{ Calibration set } & \multicolumn{5}{|c|}{ Validation set } \\
\hline & $\# \mathrm{~L}$ & SEPCV & $\mathrm{R}^{2} \mathrm{CV}$ & Bias & Slope (SE) & SEPExV & $\mathrm{R}^{2} \mathrm{ExV}$ & $\mathrm{RPD}$ \\
\hline $\mathrm{Ca}$ & 8 & 0.03 & 0.63 & -0.001 & $0.58(0.10)$ & 0.03 & 0.52 & 1.51 \\
\hline $\mathrm{K}\left(\log _{10}\right)$ & 3 & 0.18 & 0.28 & 0.002 & $0.29(0.09)$ & 0.19 & 0.25 & 1.17 \\
\hline $\mathrm{Mg}$ & 9 & 0.01 & 0.64 & 0.000 & $0.60(0.11)$ & 0.01 & 0.52 & 1.40 \\
\hline $\mathrm{Na}$ & 14 & 0.02 & 0.85 & -0.001 & $0.78(0.08)$ & 0.03 & 0.75 & 2.03 \\
\hline $\mathrm{Ca}$ & 11 & 0.02 & 0.75 & -0.001 & $0.58(0.11)$ & 0.03 & 0.47 & 1.46 \\
\hline $\mathrm{K}\left(\log _{10}\right)$ & 5 & 0.17 & 0.37 & -0.001 & $0.34(0.09)$ & 0.18 & 0.31 & 1.20 \\
\hline $\mathrm{Mg}$ & 11 & 0.00 & 0.82 & 0.000 & $0.65(0.10)$ & 0.00 & 0.57 & 1.58 \\
\hline $\mathrm{Na}$ & 12 & 0.02 & 0.89 & 0.000 & $0.73(0.09)$ & 0.03 & 0.66 & 1.76 \\
\hline $\mathrm{P}$ & 13 & 0.01 & 0.82 & 0.000 & $0.54(0.10)$ & 0.02 & 0.48 & 1.39 \\
\hline
\end{tabular}

${ }^{1} \# \mathrm{~L}=$ optimal number of model factors; SEPCV $=$ standard error of prediction of cross-validation; $\mathrm{R}^{2} \mathrm{CV}=$ coefficient of determination of cross-validation; SEPExV = standard error of prediction of external validation; $\mathrm{R}^{2} \mathrm{ExV}=$ coefficient of determination of external validation; $\mathrm{RPD}=$ ratio of prediction to deviation calculated as SD/SEPExV.

considered their predictions of $\mathrm{K}$ and $\mathrm{Na}$ (RPD of 2.7 and 3.8, respectively) in ripened cheese to be excellent, and their predictions of $\mathrm{P}(\mathrm{RPD}=1.8)$ and $\mathrm{Ca}$ and $\mathrm{Mg}$ $(\mathrm{RPD}=2.0)$ to be acceptable. Manuelian et al. $(2017 \mathrm{~b})$ successfully developed NIT prediction models in crossvalidation for $\mathrm{Ca}, \mathrm{Na}, \mathrm{P}, \mathrm{S}$, and $\mathrm{Mg}$ using a data set of 19 cheese varieties (RPD from 3.28 for $\mathrm{Na}$ to 4.57 for Ca). Lucas et al. (2008), using external validation, reported more accurate predictions for mineral content (RPD from 1.93 for $\mathrm{Mg}$ to 4.62 for $\mathrm{Ca}$ ) in commercial ripened cheeses than we found in the present study. The better prediction models from previous studies could be related to the greater amount and wider range of mineral content in the analyzed cheeses [e.g., 0.28 to $1.40 \mathrm{~g} / 100 \mathrm{~g}$ for $\mathrm{Na}$ in González-Martín et al. (2011);
0.62 to $2.80 \mathrm{~g} / 100 \mathrm{~g}$ for $\mathrm{NaCl}$ in Lucas et al. (2008); and 0.03 to $1.11 \mathrm{~g} / 100 \mathrm{~g}$ for $\mathrm{Na}$ in Manuelian et al. (2017b)]. Also, the accuracy of prediction and RPD depend on the validation process used, such as external and cross-validation (De Marchi et al., 2014) which could explain the differences between our results and those of González-Martín et al. (2011) and Manuelian et al. (2017b). However, prediction of $\mathrm{Na}$ content in mozzarella using NIT was better than that of Karoui et al. (2006a) for $\mathrm{NaCl}$ in Emmentaler using mid-infrared spectroscopy.

Our results confirm that the low mineral concentration in cheese hampers successful prediction of mineral content using near-infrared technologies. Although the prediction models were not enough accurate to predict

Table 3. Fitting statistics ${ }^{1}$ of prediction models for mineral composition (mean of 4 iterations) for Stracchino cheese using near-infrared transmittance (NIT) and near-infrared reflectance (NIR) spectroscopy

\begin{tabular}{|c|c|c|c|c|c|c|c|c|}
\hline Mineral & \multicolumn{3}{|c|}{ Calibration set } & \multicolumn{5}{|c|}{ Validation set } \\
\hline $\mathrm{Ca}$ & 14 & 0.03 & 0.80 & 0.002 & $0.73(0.12)$ & 0.05 & 0.59 & 1.50 \\
\hline $\mathrm{K}\left(\log _{10}\right)$ & 13 & 0.09 & 0.65 & 0.002 & $0.46(0.13)$ & 0.14 & 0.31 & 1.16 \\
\hline $\mathrm{Mg}^{2}$ & - & - & - & - & - & - & - & - \\
\hline $\mathrm{Na}$ & 14 & 0.04 & 0.79 & 0.001 & $0.74(0.11)$ & 0.05 & 0.62 & 1.58 \\
\hline $\mathrm{Ca}$ & 13 & 0.02 & 0.93 & 0.001 & $0.78(0.09)$ & 0.04 & 0.69 & 1.85 \\
\hline $\mathrm{K}\left(\log _{10}\right)$ & 11 & 0.08 & 0.70 & -0.007 & $0.50(0.13)$ & 0.13 & 0.35 & 1.22 \\
\hline $\mathrm{Mg}$ & 12 & 0.00 & 0.72 & 0.000 & $0.39(0.13)$ & 0.00 & 0.26 & 1.14 \\
\hline $\mathrm{Na}$ & 10 & 0.04 & 0.76 & -0.002 & $0.57(0.12)$ & 0.06 & 0.45 & 1.32 \\
\hline $\mathrm{P}$ & 12 & 0.01 & 0.93 & 0.002 & $0.82(0.09)$ & 0.03 & 0.75 & 1.95 \\
\hline
\end{tabular}

${ }^{1} \# \mathrm{~L}=$ optimal number of model factors; $\mathrm{SEPCV}=$ standard error of prediction of cross-validation; $\mathrm{R}^{2} \mathrm{CV}=$ coefficient of determination of cross-validation; SEPExV = standard error of prediction of external validation; $\mathrm{R}^{2} \mathrm{ExV}=$ coefficient of determination of external validation; $\mathrm{RPD}=$ ratio of prediction to deviation calculated as SD/SEPExV.

${ }^{2}$ Calibration for $\mathrm{Mg}$ was not achieved with NIT. 
mineral content, some achieved RPD values between 1.5 and 2.0, which may be sufficient for screening. We also observed that NIR and NIT spectroscopy performed similarly.

\section{ACKNOWLEDGMENTS}

This study was financially supported by Granarolo S.p.A (Bologna, Italy).

\section{REFERENCES}

Aburto, N. J., A. Ziolkovska, L. Hooper, P. Elliott, F. P. Cappuccio, and J. J. Meerpohl. 2013. Effect of lower sodium intake on health: Systematic review and meta-analyses. BMJ 346:f1326.

Agarwal, S., D. McCoy, W. Graves, P. D. Gerard, and S. Clark. 2011. Sodium content in retail Cheddar, Mozzarella, and process cheeses varies considerably in the United States. J. Dairy Sci. 94:16051615 .

Begley, T. H., E. Lanza, K. H. Norris, and W. R. Hruschka. 1984. Determination of sodium chloride in meat by near-infrared diffuse reflectance spectroscopy. J. Agric. Food Chem. 32:984-987.

Bonjour, J.-P., L. Guéguen, C. Palacios, M. J. Shearer, and C. M. Weaver. 2009. Minerals and vitamins in bone health: The potential value of dietary enhancement. Br. J. Nutr. 101:1581-1596.

Brereton, R. G. 2015. The Mahalanobis distance and its relationship to principal component scores. J. Chemometr. 29:143-145.

Büning-Pfaue, H. 2003. Analysis of water in food by near infrared spectroscopy. Food Chem. 82:107-115.

De Angelis, M., S. de Candia, M. P. Calasso, M. Faccia, T. P. Guinee, M. C. Simonetti, and M. Gobbetti. 2008. Selection and use of autochthonous multiple strain cultures for the manufacture of highmoisture traditional Mozzarella cheese. Int. J. Food Microbiol. 125:123-132.

De Marchi, M., C. L. Manuelian, S. Ton, D. Manfrin, M. Meneghesso, M. Cassandro, and M. Penasa. 2017. Prediction of sodium content in commercial processed meat products using near infrared spectroscopy. Meat Sci. 125:61-65.

De Marchi, M., V. Toffanin, M. Cassandro, and M. Penasa. 2014. Invited review: Mid-infrared spectroscopy as phenotyping tool for milk traits. J. Dairy Sci. 97:1171-1186.

Gambelli, L., P. Belloni, G. Ingrao, L. Pizzoferrato, and G. P. Santaroni. 1999. Minerals and trace elements in some Italian dairy products. J. Food Compos. Anal. 12:27-35.

González-Martín, I., J. M. Hernández-Hierro, I. Revilla, A. VivarQuintana, and I. Lobos Ortega. 2011. The mineral composition (Ca, P, Mg, K, Na) in cheeses (cow's, ewe's and goat's) with different ripening times using near infrared spectroscopy with a fibreoptic probe. Food Chem. 127:147-152.
Iwamoto, M., S. Kawano, and Y. Ozaki. 1995. An overview of research and development of near infrared spectroscopy in Japan. J. Near Infrared Spectrosc. 3:179-189.

Jana, A. H., and P. K. Mandal. 2011. Manufacturing and quality of Mozzarella cheese: A review. Int. J. Dairy Sci. 6:199-226.

Johnson, M. E., R. Kapoor, D. J. McMahon, D. R. McCoy, and R. G. Narasimmon. 2009. Reduction of sodium and fat levels in natural and processed cheeses: Scientific and technological aspects. Compr. Rev. Food Sci. Food Saf. 8:252-268.

Karoui, R., A. M. Mouazen, É. Dufour, L. Pillonel, D. Picque, J.-O. Bosset, and J. De Baerdemaeker. 2006a. Mid-infrared spectrometry: A tool for the determination of chemical parameters in Emmental cheeses produced during winter. Lait 86:83-97.

Karoui, R., A. M. Mouazen, É. Dufour, L. Pillonel, E. Schaller, J. De Baerdemaeker, and J.-O. Bosset. 2006b. Chemical characterisation of European Emmental cheeses by near infrared spectroscopy using chemometric tools. Int. Dairy J. 16:1211-1217.

Lante, A., G. Lomolino, M. Cagnin, and P. Spettoli. 2006. Content and characterisation of minerals in milk and in Crescenza and Squacquerone Italian fresh cheeses by ICP-OES. Food Contr. $17: 229-233$.

Lombardi-Boccia, G., A. Aguzzi, M. Cappelloni, G. Di Lullo, and M. Lucarini. 2003. Total-diet study: Dietary intakes of macro elements and trace elements in Italy. Br. J. Nutr. 90:1117-1121.

Lucas, A., D. Andueza, E. Rock, and B. Martin. 2008. Prediction of dry matter, fat, $\mathrm{pH}$, vitamins, minerals, carotenoids, total antioxidant capacity, and color in fresh and freeze-dried cheeses by visible-near-infrared reflectance spectroscopy. J. Agric. Food Chem. $56: 6801-6808$

Manley, M. 2014. Near-infrared spectroscopy and hyperspectral imaging: Non-destructive analysis of biological materials. Chem. Soc. Rev. 43:8200-8214.

Manuelian, C. L., S. Currò, M. Penasa, M. Cassandro, and M. De Marchi. 2017a. Characterization of major and trace minerals, fatty acid composition, and cholesterol content of Protected Designation of Origin cheeses. J. Dairy Sci. 100:3384-3395. https://doi.org/ https://doi.org/10.3168/jds.2016-12059.

Manuelian, C. L., S. Currò, M. Penasa, M. Cassandro, and M. De Marchi. 2017b. Prediction of minerals, fatty acid composition and cholesterol content of commercial cheeses by near infrared transmittance spectroscopy. Int. Dairy J. 71(8):107-113. https://doi. org/10.1016/j.idairyj.2017.03.011.

Matthews, K., and M. Strong. 2005. Salt-Its role in meat products and the industry's action plan to reduce it. Nutr. Bull. 30:55-61.

Sinnaeve, G., P. Dardenne, R. Agneessens, and R. Biston. 1994. The use of near infrared spectroscopy for the analysis of fresh grass silage. J. Near Infrared Spectrosc. 2:79-84.

Woodcock, T., C. C. Fagan, C. P. O'Donnell, and G. Downey. 2008. Application of near and mid-infrared spectroscopy to determine cheese quality and authenticity. Food Bioproc. Techol. 1:117-129. 